\title{
Differential sensitivity to oxygen among the bacteriochlorophylls $g$ in the type-I reaction centers of Heliobacterium modesticaldum
}

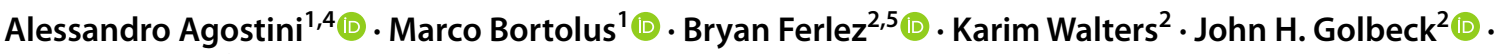 \\ Art van der $\mathrm{Est}^{3}{ }^{-1}$. Donatella Carbonera ${ }^{1}$ (D)
}

Received: 1 March 2021 / Accepted: 28 April 2021 / Published online: 20 May 2021

(c) The Author(s), under exclusive licence to European Photochemistry Association, European Society for Photobiology 2021

\begin{abstract}
The type-I, homodimeric photosynthetic reaction center (RC) of Heliobacteria (HbRC) is the only known RC in which bacteriochlorophyll $g$ (BChl $g$ ) is found. It is also simpler than other RCs, having the smallest number of protein subunits and bound chromophores of any type-I RC. In the presence of oxygen, BChl $g$ isomerizes to $8^{1}$-hydroxychlorophyll $a_{\mathrm{F}}(\mathrm{Chl}$ $a_{\mathrm{F}}$ ). This naturally occurring process provides a way of altering the chlorophylls and studying the effect of these changes on energy and electron transfer. Transient absorbance difference spectroscopy reveals that triplet-state formation occurs in the antenna chlorophylls of HbRCs but does not provide site-specific information. Here, we report on an extended optically detected magnetic resonance (ODMR) study of the antenna triplet states in HbRCs with differing levels of conversion of $\mathrm{BChl} g$ to Chl $a_{\mathrm{F}}$. The data reveal pools of BChl $g$ molecules with different triplet zero-field splitting parameters and different susceptibilities to chemical oxidation. By relating the detailed spectroscopic characteristics derived from the ODMR data to the recently solved crystallographic structure, we have tentatively identified $\mathrm{BChl} g$ molecules in which the probability of triplet formation is high and sites at which $\mathrm{BChl} g$ conversion is more likely, providing useful information about the fate of the excitation in the complex.
\end{abstract}

Keywords Type-I photosystem $\cdot$ Optically detected magnetic resonance $\cdot$ Triplet state $\cdot$ Bacteriochlorophyll $g \cdot$ Oxygen sensitivity $\cdot$ Chlorophyll $a$

Pushing the limits of flash photolysis to unravel the secrets of biological electron and proton transfer - a topical issue in honour of Klaus Brettel.

Art van der Est

avde@brocku.ca

$\triangle$ Donatella Carbonera

donatella.carbonera@unipd.it

1 Department of Chemical Sciences, University of Padova, Via Marzolo, 1, 35131 Padua, Italy

2 Department of Biochemistry and Molecular Biology, The Pennsylvania State University, University Park, PA 16802, USA

3 Department of Chemistry, Brock University, 1812 Sir Isaac Brock, Way, Saint Catharines, ON L2S 3A1, Canada

4 Present Address: Biology Centre, Czech Academy of Sciences, Institute of Plant Molecular Biology, Branisovska 31, 37005 České Budějovice, Czechia

5 Present Address: Department of Biochemistry and Molecular Biology and MSU-DOE Plant Research Laboratory, Michigan State University, East Lansing, MI, USA

\section{Introduction}

Heliobacteria are strict anaerobes, found mainly in terrestrial environments, which play an invaluable role in the process of nitrogen fixation [1,2]. These photoheterotrophic organisms employ bacteriochlorophyll (BChl) $g$ as the main chromophore of their photosynthetic apparatus, selected for its intense $Q_{y}\left(\mathrm{~S}_{0} \rightarrow \mathrm{S}_{1}\right)$ absorption maximum in the nearinfrared region of the spectrum $[1,3]$. This allows the organism to make better use of the available light in the soil environment, which is dominated by longer wavelengths that penetrate to greater depth [4]. An important feature of $\mathrm{BChl}$ $g$ is the ethylidene substituent at C-8 (Fig. 1a) [3]. This group is especially susceptible to oxidation and in the presence of oxygen, BChl $g$ is converted to $8^{1}$-hydroxychlorophyll $a_{\mathrm{F}}$ (Chl $\left.a_{\mathrm{F}}\right)$, [5-8] which is spectroscopically indistinguishable from chlorophyll $a(\mathrm{Chl} a)[8,9]$.

The reaction center of Heliobacterium modesticaldum is a type-I [10] homodimeric [11] complex, binding 54 BChl $g$, 4 BChl $g$ ' $\left(13^{2}\right.$ epimer of BChl $\left.g\right), 2$ Chl $a_{\mathrm{F}}, 2$ 

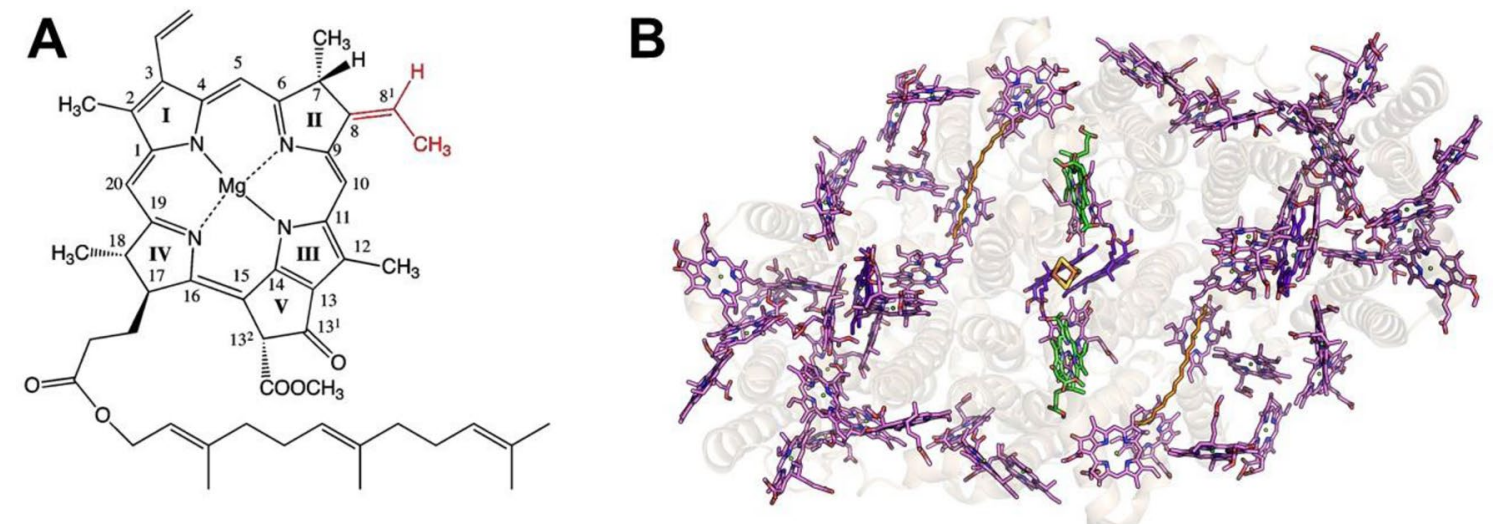

Fig. 1 a Structure and IUPAC numbering scheme for BChl $g$ (the ethylidene group has been highlighted in red). b Crystallographic structure of $H$. modesticaldum RC (PDB: 5V8K [12]), in which the homodimeric architecture is recognizable. The cofactors BChl $g$ (pink), BChl $g^{\prime}$ (purple), Chl $a_{\mathrm{F}}$ (green) and diaponeurosporenes (orange) are highlighted while the protein scaffold is shown as beige cartoons. The farnesyl chains of the chlorophylls have been omitted for clarity 4,4'-diaponeurosporene, and a $\mathrm{Fe}_{4} \mathrm{~S}_{4}$ center, as clearly discernable in the crystallographic structure [12] (Fig. 1b). Menaquinone has also been found to be present in the complex, [10, 13] but appears to be weakly coupled and easily lost during the purification process [12]. Its role in the reaction center of heliobacteria is still under debate, [14-17] and it has been shown that electron transport through the complex is not affected by removal of menaquinone and there is no direct spectroscopic evidence for the involvement of menaquinone in electron transfer to $F_{X}$ under physiological conditions $[14,15,18]$. However, a recent study of menaquinone reduction suggests that HbRC may switch between reduction of soluble ferredoxin and lipophilic menaquinone under different conditions [19].

Recently, the sensitivity towards oxidation of the BChl $g$ bound by the complex has been characterized, with a focus on the special pair. The oxidation of BChl $g$ ' was found to occur at the same rate as BChl $g$, suggesting that the BChl molecules that constitute the primary donor, have a similar accessibility to oxygen as the antenna BChls [8]. The activity of the RC was found to be diminished as the conversion of BChl $g$ to $\mathrm{Chl} a_{F}$ occurred, but the correlation was not linear. The observed relationship between activity and the degree of BChl $g$ conversion could be explained by proposing that the complex becomes inactive when both of the constituent BChl $g$ ' molecules of the $\mathrm{P}_{800}$ are converted but that complexes containing a BChl $g$ '/ Chl $a_{F}$ ' dimer are still able to perform electron transfer. Transient EPR data also provided evidence of an active, altered primary donor that was assigned to the heterodimeric BChl $g$ '/Chl $a_{\mathrm{F}}$ ' species. In addition to the charge separation, the transient EPR data showed the formation of antenna triplet states that could be assigned to ${ }^{3} \mathrm{BChl}$ $g$ and ${ }^{3} \mathrm{Chl} a_{\mathrm{F}}$. The ratio of these two species was found to change as conversion of $\mathrm{BChl} g$ to $\mathrm{Chl} a_{\mathrm{F}}$ took place.

The alteration of the antenna chlorophyll molecules provides a unique opportunity to study the effect of the chlorophyll properties on the energy transfer process in a photosynthetic reaction center. Moreover, the recently published X-ray crystal structure makes it possible to correlate changes in the energy transfer with structural features of the complex. Because triplet formation occurs in the antenna chlorophylls of HbRCs and changes in the triplet states are observed by transient EPR when conversion of BChl $g$ to $\mathrm{Chl} a_{F}$ occurs, we have chosen to study the partially oxidized complexes using optically detected magnetic resonance (ODMR). This experiment can be conducted as fluorescence detected magnetic resonance (FDMR) or absorption detected magnetic resonance, and both methods provide a very detailed picture of the properties of the triplet states. The technique, being a double resonance spectroscopy, is highly selective and allows the magnetic and optical properties of the molecules carrying the triplet states to be monitored at the same time and different local environments to be distinguished even in complicated multi-chromophoric systems, such as RCs. By comparing oxidized and anoxic control samples, we will show that among the BChl $g$ chromophores that form triplet states upon excitation, several molecules with different local environments exist in the anoxic sample. Further, we will show that these molecules have different sensitivities to oxygen, suggesting different locations within the complex. Using the X-ray crystal structure [12] of the complex and computations of the excitonic coupling between the BChl $g$ chromophores, we will also determine possible locations for the different chromophores. 


\section{Experimental and theoretical methods}

\subsection{Sample preparation}

Preparation and purification of heliobacterial reaction centers (HbRCs) were conducted as previously described, [20] carrying out all manipulations under strict anoxic conditions and dim green light. The oxidized sample was prepared by exposing HbRCs in $50 \mathrm{mM}$ MOPS $\mathrm{pH} 7.0,0.02 \%$ dodecyl maltoside to oxygen in the dark for $8 \mathrm{~h}$ at $298 \mathrm{~K}$ as described in Ferlez et al. [8]. The final sample composition was $100 \mu \mathrm{M}$ BChl $g$ in buffer containing $10 \mathrm{mM}$ MOPS $\mathrm{pH}$ 7.0, $0.004 \%$ dodecyl maltoside, $10 \mathrm{mM}$ sodium ascorbate, and $56 \%$ glycerol. The samples were inserted into the cryostat pre-cooled at $60 \mathrm{~K}$ and subsequently quickly cooled to $1.8 \mathrm{~K}$, to fast-freeze the solutions, obtaining homogeneous and transparent matrices.

\subsection{Transient absorption measurements}

Transient absorption measurements were carried out at room temperature on samples prepared under the same conditions as for the ODMR experiments. Time traces of the absorbance changes at $830 \mathrm{~nm}$ were measured using a home-built double-beam transient time-resolved optical spectrometer described in detail by Vassiliev et al. [21]. Actinic laser flashes at $532 \mathrm{~nm}$ were provided by a frequency-doubled Minilite II high-energy Nd:YAG with a pulse energy 4-50 mJ and pulse width of 3-7 ns. The transient absorption change at $830 \mathrm{~nm}$, was monitored with a $100 \mathrm{~mW}$ diode laser (Crystal laser, model number DL830-100-O). The beam from the diode laser was divided into measurement and reference beams using a 70:30 beam-splitter. The two beams were detected by a pair of balanced detectors. An $830 \mathrm{~nm}$ interference filter (FL830-10, Thor labs) and a $532 \mathrm{~nm}$ notch filter (NF533-17, Thor Labs) were placed in front of each detector to prevent interference from the $532 \mathrm{~nm}$ actinic beam. The absorption change was signal averaged for 512 scans.

\subsection{ODMR experiments}

ODMR spectra were acquired in a home-built set-up which has been previously described in detail [22-24]. The principle of the ODMR technique has been described extensively in several reviews [25, 26]. To briefly describe the technique, the light from a halogen lamp ( $250 \mathrm{~W}$, Philips) is focused on the sample cell, which is immersed in a bath helium cryostat (all measurements were carried out at a temperature of $1.8 \mathrm{~K}$ ), after being filtered through either a $5 \mathrm{~cm} \mathrm{CuSO}_{4}$ solution (FDMR spectra) or a $10 \mathrm{~cm}$ water filter (triplet minus singlet $\mathrm{T}-\mathrm{S}$, absorption-detected spectra). In FDMR experiments, the fluorescence is detected through bandpass filters (characterized by a full width at half maximum of about $10 \mathrm{~nm}$ ) using a photodiode placed at $90^{\circ}$ with respect to the excitation light direction, while in absorption-detected experiments, the light transmittance is detected with the standard straight geometry through a monochromator (Jobin Yvon, mod. HR250) using the same photodiode employed for the FDMR measurements. By sweeping the microwave frequency (MW source HP8559b, sweep oscillator equipped with a HP83522s plug-in and amplified by a TWT ScoNucletudes mod. 10-46-30 amplifier) while detecting the absorption or the fluorescence changes at specifics wavelengths, the resonance transitions between spin sublevels of the triplet states can be determined. The microwaves are on/ off amplitude modulated for selective amplification and the signal from the detector is demodulated and amplified using a lock-in amplifier (EG\&G, mod 5210). The analog output is connected to a computer-controlled analog to digital converter. The microwave resonator, where the sample cell is inserted, consists of a slow pitch helix. FDMR spectra are presented as $\Delta \mathrm{F} / \mathrm{F}$ versus microwave frequency, where $\Delta \mathrm{F}$ is the fluorescence change induced by the resonant microwave field and F is the steady-state fluorescence detected by the photodiode at the selected wavelength.

Once the resonance frequencies of the transitions have been determined (from the FDMR spectra, for example), microwave-induced $\mathrm{T}-\mathrm{S}$ spectra can be collected by fixing the microwave frequency at a resonant value and sweeping the absorption detection wavelength [27]. T-S spectra are presented as $\Delta \mathrm{I} / \mathrm{I}$ versus wavelength, where $\Delta \mathrm{I}$ is the transmittance change induced by the resonant microwave field at a certain a wavelength, and I is the steady-state transmittance detected by the photodiode. It can be demonstrated [28] that for small $\Delta \mathrm{I}, \Delta \mathrm{I} / \mathrm{I}$ is proportional to the absorbance change induced by the resonant microwave field (i.e., $\Delta \mathrm{A}$ ). Compared to optical time-resolved absorbance spectroscopy on the triplet state, the ODMR technique allows selection (by the resonant microwave field) of specific triplet populations present in the sample and in this way, well-resolved $\mathrm{T}-\mathrm{S}$ spectra associated with specific chromophores can be obtained.

\subsection{Excitonic coupling calculation}

The excitonic coupling between each pair of chromophores in the HbRC structure [12] was calculated in the framework of the point dipole approximation. This approach, although basic when compared to more advanced methodologies, has been shown to be suitable for describing tetrapyrrole $Q_{y}-Q_{y}$ interactions in many systems $[29,30]$. The calculation was limited to the $Q_{y}$ transitions of the $58 \mathrm{BChl} g$ and $g$ ' and 2 Chls $a_{\mathrm{F}}$ chromophores bound in the homodimeric complex, 
retrieving the orientation of the transition dipole moments from the structure of HbRC [12]. Previous TD-DFT calculations performed by Kitoh-Nishioka et al. [31] on BChl $g$ and BChl $g$ ' showed that the orientations and moduli of their $Q_{y}$ transitions were very similar to those of $\mathrm{BChl} a$, due to their similar structure. Therefore, transition dipole moments of 6.5 and 4.6 Debye have been adopted for all the BChls $g$ and Chls $a_{\mathrm{F}}$, respectively [32]. The transition dipole moment orientations for both types of chromophores were derived from the positions of the nitrogen atoms of the pyrrole rings A and C, according to Madjet et al. [33].

The point dipole coupling term of the $j$-th and $i$-th chromophores, $V_{j i}$, is calculated as:

$V_{i j}=\frac{\mathrm{f}_{1}}{4 \pi \varepsilon_{0}}\left[\frac{\boldsymbol{\mu}_{i} \cdot \boldsymbol{\mu}_{j}}{R_{i j}^{3}}-3 \frac{\left(\boldsymbol{\mu}_{i} \cdot \boldsymbol{R}_{i j}\right)\left(\boldsymbol{\mu}_{j} \cdot \boldsymbol{R}_{i j}\right)}{R_{i j}^{5}}\right]$

where $\boldsymbol{\mu}_{i, j}$ is the transition dipole moment at distance $\boldsymbol{R}_{i j}$ and $\varepsilon_{0}$ is the dielectric constant in vacuum. For the local field correction $\mathrm{f}_{1}$, a value of 0.56 has been adopted, following a recent study on HbRC from Kitoh-Nishioka et al. [31] in which this correction term was optimized to reproduce Coulomb couplings between pairs of BChls obtained from ab initio electrostatic potentials derived from TD-DFT calculations performed on BChls $g$ and $g$ '. For the P800 special pair, the value $V=234 \mathrm{~cm}^{-1}$ calculated at a configurationinteraction singles level as reported by from Kitoh-Nishioka et al. [31] was employed, since the point dipole coupling method yields unreliable results for the strongly coupled special pair [31,34]. All site energies for BChls $g$ and $g$ ' are set at $12,658 \mathrm{~cm}^{-1}$, while Chls $a_{\mathrm{F}}$ site energies are set at $14,925 \mathrm{~cm}^{-1}$.

\section{Results}

\subsection{Time resolved optical spectroscopy}

Figure 2 shows the steady-state absorption spectra of HbRCs at room temperature under anoxic conditions (black spectrum) and after exposure to oxygen for $8 \mathrm{~h}$ (green spectrum). The strong band at $800 \mathrm{~nm}$ in the spectrum of the anoxic sample is the $Q_{y}$ band of $\mathrm{BChl} g$. The much weaker band at $670 \mathrm{~nm}$ is the $Q_{y}$ band of $\mathrm{Chl} a_{\mathrm{F}}$. As can be seen, exposure to oxygen for $8 \mathrm{~h}$ leads to a decrease in the intensity of the $800 \mathrm{~nm}$ band and an increase of the $670 \mathrm{~nm}$ band as BChl $g$ is converted to $\mathrm{Chl} a_{\mathrm{F}}$. In anoxic samples, the primary donor, $\mathrm{P}_{800}$, in the electron transfer chain is a $\mathrm{BChl} g$ dimer that can be seen at the center of the structure in Fig. 1b. The primary acceptor $\mathrm{A}_{0}$ is either of the two Chl $a_{\mathrm{F}}$ cofactors shown in green in Fig. 1b. Previous studies have shown that excitation of anoxic samples leads to bleaching of the $800 \mathrm{~nm}$ and $670 \mathrm{~nm}$ bands as $\mathrm{P}_{800}{ }^{+} \mathrm{A}_{0}{ }^{-}$is formed [35]. In addition,

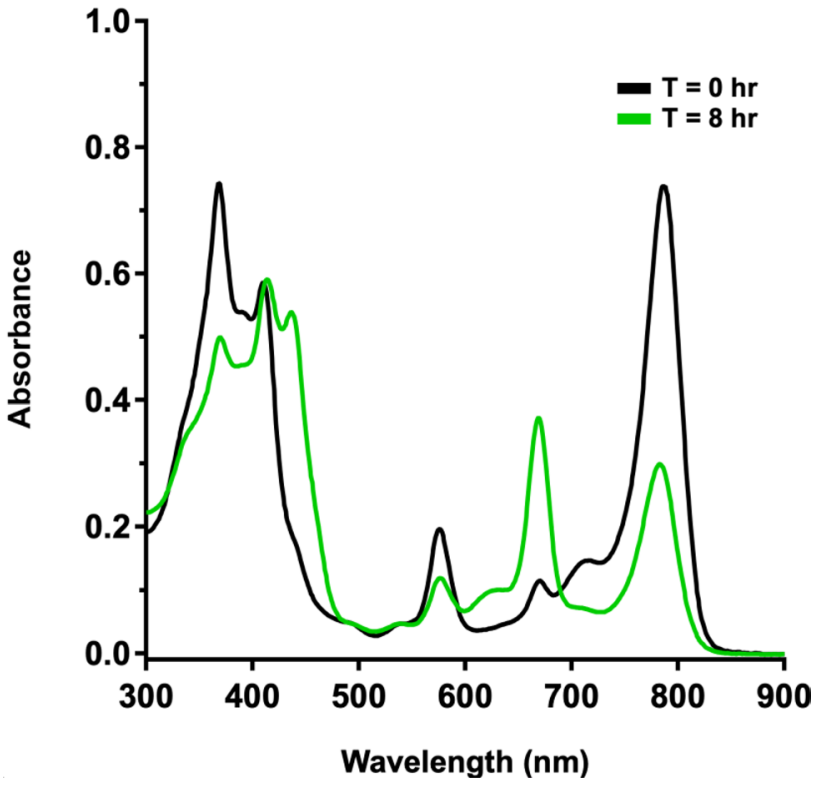

Fig. 2 Steady-state room temperature absorption spectra of HbRCs showing the effect of oxygen exposure. Black spectrum: no exposure to oxygen. Green spectrum: exposure to atmospheric $\mathrm{O}_{2}$ for $8 \mathrm{~h}$ in the dark. The oxygen-exposed sample has approximately $40.6 \% \mathrm{BChl} g$ remaining based on the ratio of the maximum absorbance values of the $Q_{y}$ peak for the $T=8 \mathrm{~h}$ and $T=0 \mathrm{~h}$ samples

a broad absorption band due to $\mathrm{P}_{800}{ }^{+}$is expected about $30 \mathrm{~nm}$ to the red of the bleach. Since chlorophyll tripletstate absorption is also expected to occur in this wavelength range, transient absorbance measurements $830 \mathrm{~nm}$ can be used to probe for charge separation and the possible formation of triplet states.

The room temperature light-induced absorption changes at $830 \mathrm{~nm}$ of anoxic HbRCs containing $80 \%$ BChl $g$ and $20 \% \mathrm{Chl} a$ are shown in Fig. 3, for different energies of the actinic laser flash. The multi-exponential fits of the data (red traces) reveal two kinetic phases with lifetimes of roughly $185 \mu \mathrm{s}$ and $10 \mathrm{~ms}$. The non-saturating behavior of the fast kinetic phase as a function of laser flash intensity is consistent with its identification as the relaxation of antenna chlorophyll triplet states. In contrast, the amplitude of the slow kinetic phase reaches an asymptotic limit as a function of light intensity; this and the characteristic lifetime of 10 ms identify the slow kinetic phase as charge recombination between $\mathrm{F}_{\mathrm{X}}{ }^{-}$and $\mathrm{P}_{800}{ }^{+}$that occurs in the absence of fast solution electron donors and acceptors. It should be noted that even though a relatively large amount of antenna chlorophyll triplet is observed, there is likely no deleterious effect from active oxygen species, as heliobacteria are strict anaerobes.

We are interested in identifying possible sites in the HbRC where triplet states are formed to better understand how triplet formation is avoided in oxygenic organisms. The 
Fig. 3 Transient absorption kinetic traces of intact HbRCs at room temperature as a function of the actinic laser flash energy a $15 \mathrm{~mJ}$, b $5 \mathrm{~mJ}$ and c $0.35 \mathrm{~mJ}$. The experimental data shown in blue are the average of 512 events. The red traces are a multi-exponential fit of the data using the Marquardt least squares algorithm

fact that BChl $g$ can be converted to Chl $a$ means that it is possible to alter the antenna and study the effect of the alteration on triplet-state formation. This information can then act as a guide to identifying possible sites. However, single-wavelength transient absorption difference spectroscopy does not provide much information about the location of the triplet states. Thus, we have carried out ODMR studies, which provide much more detail about the local environment of triplet states.

\subsection{FDMR spectra}

Figure 4 shows a comparison of the low temperature fluorescence spectrum of HbRC, under anoxic conditions (black spectrum) and after exposure to oxygen for $8 \mathrm{~h}$ in the dark (green spectrum). The two spectra have been normalized to the same maximum intensity. The spectrum of the anoxic sample is dominated by a narrow band peaking at $817 \mathrm{~nm}$, originating from $\mathrm{BChl} g$. A weak contribution at about $675 \mathrm{~nm}$ can also be detected and is assigned to a minor amount of $\mathrm{Chl} a_{\mathrm{F}}$ fluorescence. The exposure of the sample to oxygen leads to partial conversion of BChl $g$ into Chl $a_{\mathrm{F}}[5,7,8]$ and a change of color from brown to green. Correspondingly, a large increase in the $\mathrm{Chl} a_{\mathrm{F}}$ emission at $680 \mathrm{~nm}$ relative to the BChl $g$ band is observed along with broadening and a slight hypsochromic shift of the BChl $g$ band at $815 \mathrm{~nm}$.

The well-resolved fluorescence bands of ${ }^{3} \mathrm{BChl} g$ and ${ }^{3} \mathrm{Chl}$ $a_{\mathrm{F}}$ and the substantial difference in their zero-field splitting parameters allow FDMR spectra of the steady-state populations of these two chromophores generated in HbRC upon illumination to be collected selectively at cryogenic temperatures. Because steady-state illumination is used for the FDMR experiments, the number of photons per chlorophyll on the time scale of the experiment is significantly higher than in the transient absorption experiments and a sufficient yield of triplet states can be expected. In Fig. 5, the $|\mathrm{D}|-|\mathrm{E}|$ and $|\mathrm{D}|+\mid \mathrm{El}$ FDMR transitions, caused by an increase of the fluorescence emission intensity in the near-infrared window when a change of triplet population is induced by resonant microwaves, are shown both for the anoxic sample and for the sample which has been exposed to oxygen for $8 \mathrm{~h}$. The detection in this wavelength region identifies the emitters as BChls $g$, and the frequencies at which the $|\mathrm{D}|-|\mathrm{E}|$ and $|\mathrm{D}|+\mid$ El FDMR transitions are detected are compatible with the localization of the triplet state on BChl $g$ molecules [36].

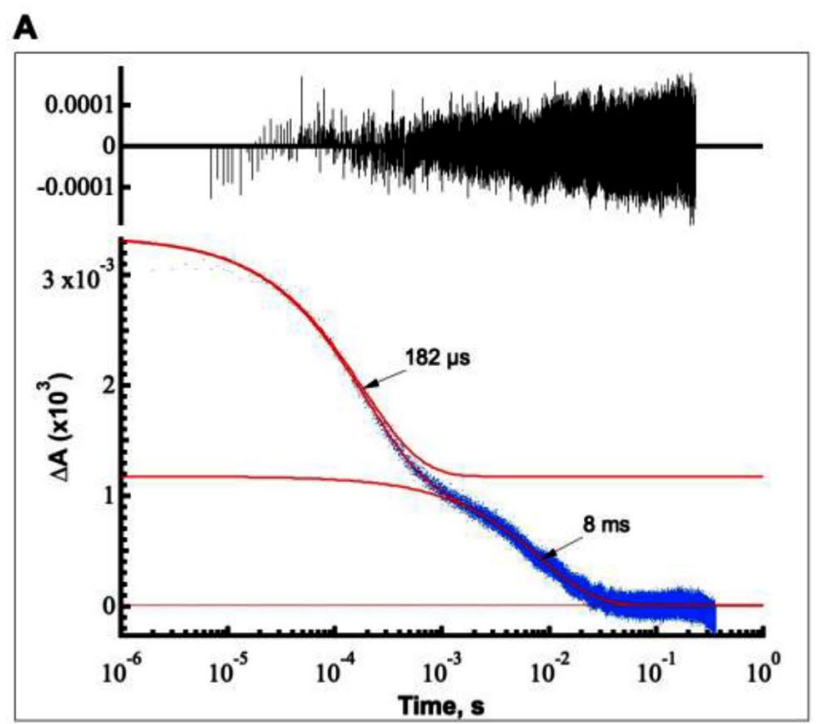

B
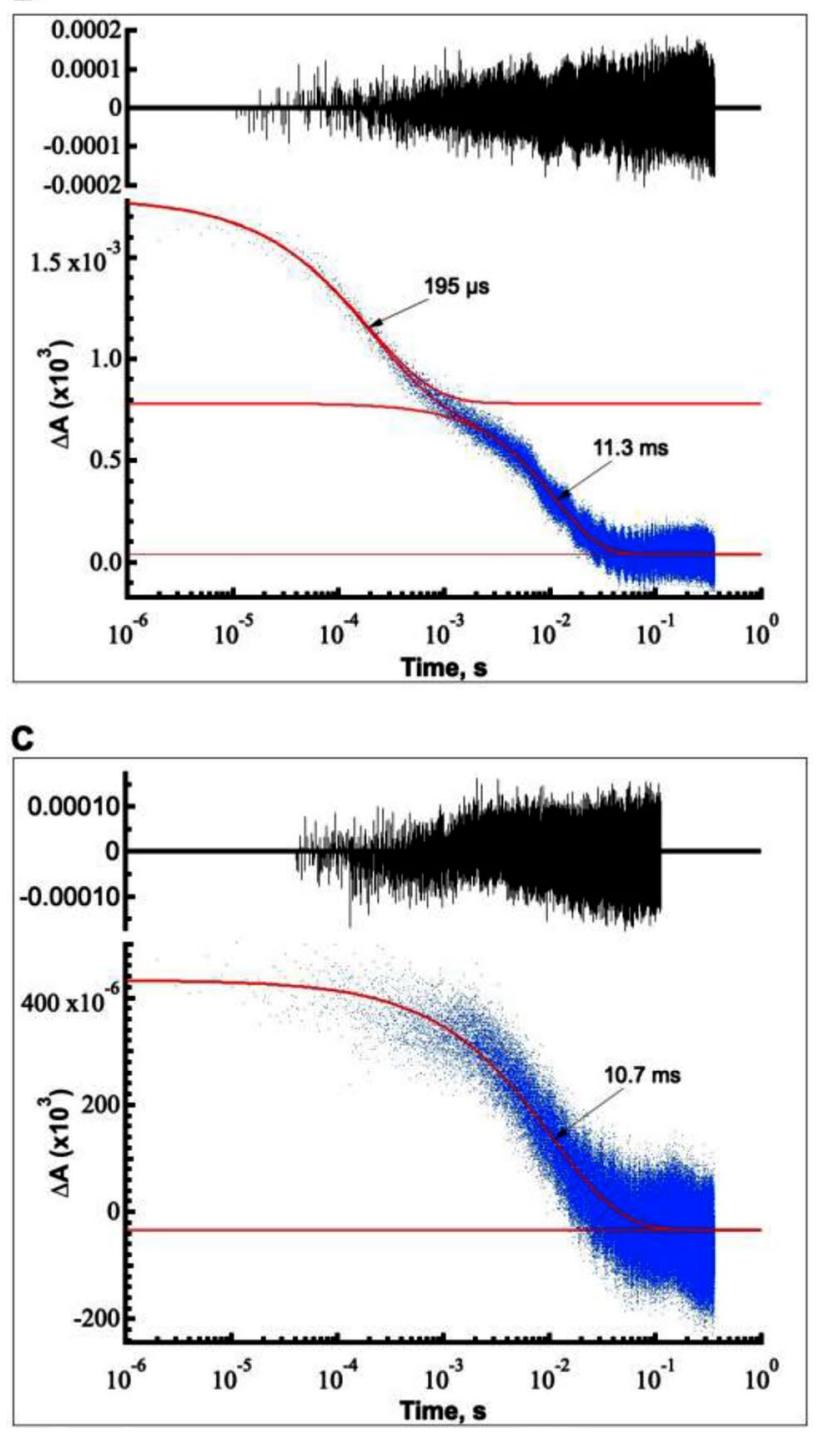


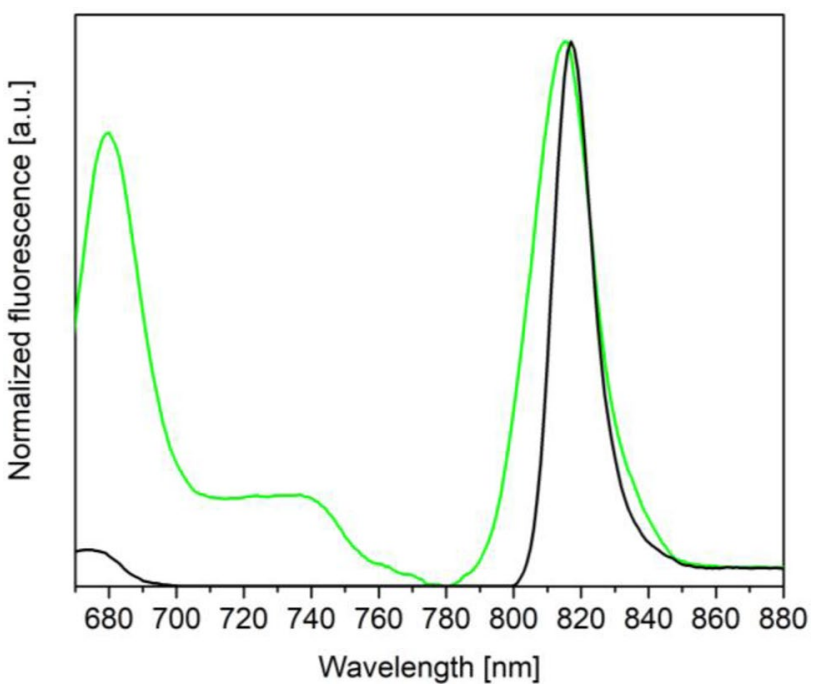

Fig. 4 Normalized fluorescence spectra of HbRCs at $1.8 \mathrm{~K}$. (black) anoxic conditions, (green) after $8 \mathrm{~h}$ of exposure to oxygen in the dark

The marked asymmetry of the $|\mathrm{D}|+|\mathrm{E}|$ transition and the wavelength dependence of the two transitions monitored at representative emission wavelengths across the fluorescence

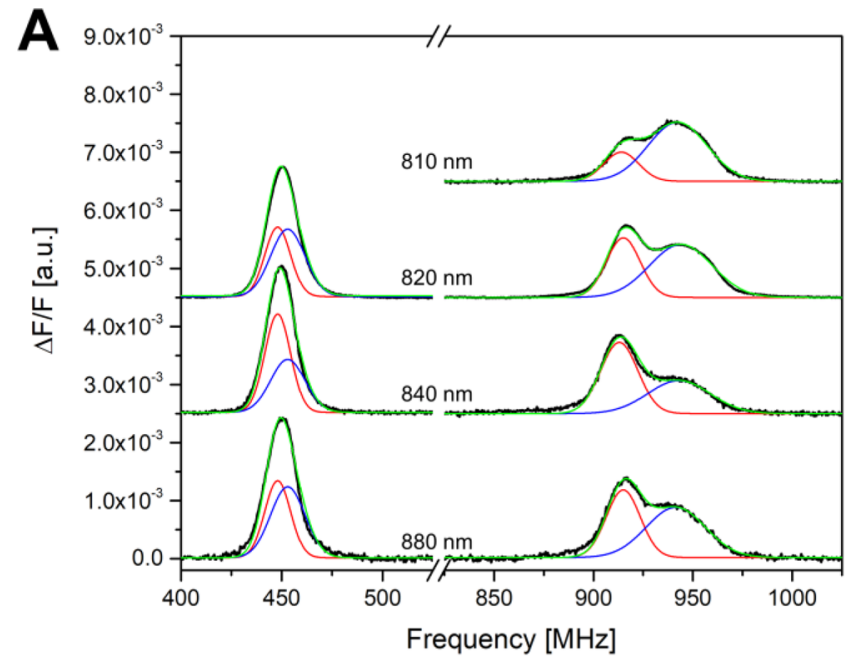

Fig. $5{ }^{3}$ BChl $g$ FDMR spectra of HbRC. a anoxic control, b 8 h of exposure to oxygen in the dark. $|\mathrm{D}|+|\mathrm{E}|$ and $|\mathrm{D}|-|\mathrm{E}|$ transitions of the FDMR spectra (black lines) of ${ }^{3} \mathrm{BChl} g$ detected at different wavelengths in the $800-880 \mathrm{~nm}$ range, as indicated. Amplitude modulation emission band of BChl $g$ imply the presence of at least two different ${ }^{3} \mathrm{BChl} g$ species. To distinguish the different ${ }^{3} \mathrm{BChl}$ $g$ populations that contribute to the FDMR signals, the data were globally fitted with a linear combination of Gaussian functions. As described in great detail in previous studies, [23, 37] the global fit imposes the constraint that the Gaussian components belonging to the same triplet population in the two transitions $(|\mathrm{D}|-\mid \mathrm{El}$ and $|\mathrm{D}|+\mid \mathrm{El})$ must have the same microwave-induced fluorescence spectrum. The FDMR spectra were found to be satisfactorily described with a minimal number of two Gaussian components, representing two distinct ${ }^{3} \mathrm{BChl} g$ populations, with the parameters reported in Table 1 . Note that only the absolute values of $\mathrm{D}$ and $\mathrm{E}$ parameters can be determined from ODMR experiments. However, the parameter $\mathrm{D}$ is known to be positive for the triplet state of porphyrin derivatives [37]. Both ${ }^{3} \mathrm{BChls}$ $g$ have a very large $|E|$ value. If the same definition of the ZFS axes is used for both BChls $g$, the IEl value of one of them exceeds $\mid \mathrm{DI} / 3$. This characteristic was pointed out in a previous work by Vrieze, et al. [36] who found, a relatively high value of $\mathrm{IEl}$ for $\mathrm{BChl} \mathrm{g}$ in organic solvents and H. chlorum that is quite unlike the values of $\mathrm{E}$ of other (B) Chls. This large value of $\mathrm{IEl}$ is likely due to an increase in

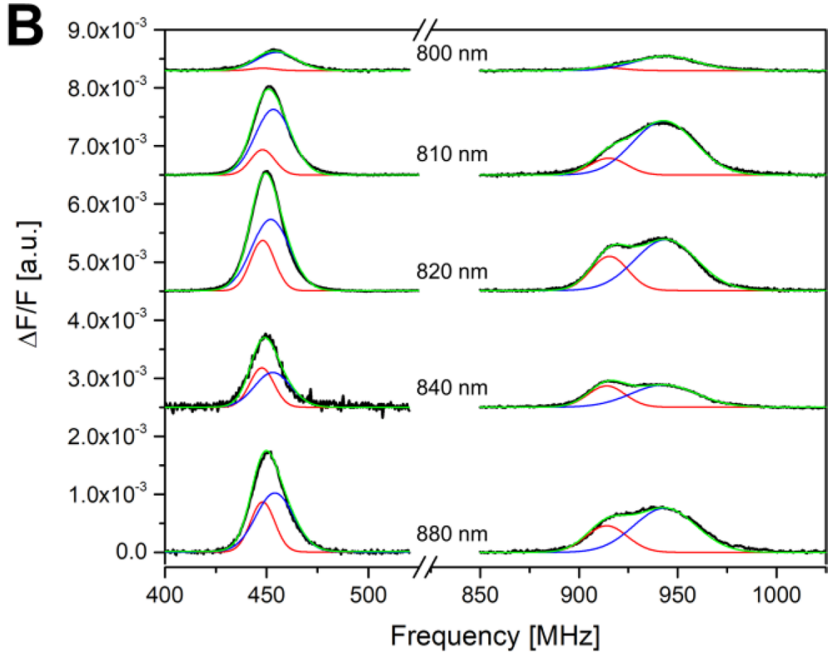

$33 \mathrm{~Hz}$, time constant $100 \mathrm{~ms}$, temperature $1.8 \mathrm{~K}$. The spectra have been vertically shifted for better comparison. Reconstruction (green) of the experimental spectra with Gaussian components (blue and red). Fitting parameters reported in Table 1
Table 1 Zero-field splitting parameters of ${ }^{3} \mathrm{BChl} g$ in HbRCs from global deconvolution of FDMR data (see Fig. 5)

\begin{tabular}{|c|c|c|c|c|c|c|c|}
\hline \multirow[t]{2}{*}{ Triplet } & \multicolumn{2}{|l|}{$|\mathbf{D}|-|\mathbf{E}|$} & \multicolumn{2}{|l|}{$|\mathbf{D}|+|\mathbf{E}|$} & \multirow[t]{2}{*}{ IDI $\left[\mathrm{cm}^{-1}\right]$} & \multirow[t]{2}{*}{$|\mathbf{E}|\left[\mathrm{cm}^{-1}\right]$} & \multirow{2}{*}{$\begin{array}{l}\text { Singlet-singlet } \\
\text { absorption } \\
{[\mathrm{nm}]}\end{array}$} \\
\hline & Peak [MHz] & $\begin{array}{l}\text { FWHM } \\
{[\mathrm{MHz}]}\end{array}$ & Peak [MHz] & $\begin{array}{l}\text { FWHM } \\
{[\mathrm{MHz}]}\end{array}$ & & & \\
\hline BChl $g_{1}$ & 448 & 14 & 914 & 22 & 0.0227 & 0.00776 & 815 \\
\hline BChl $g_{2}$ & 454 & 22 & 944 & 37 & 0.0233 & 0.00816 & 798 \\
\hline
\end{tabular}

Estimated error $\pm 0.5 \%$ 
the asymmetry of the spin density distribution caused by the presence of the exo vinyl group at position 3 on ring I, which is not found in $\mathrm{BChl} a$ and $\mathrm{BChl} b$. They also reported that the $\mid \mathrm{El}$ value for the triplet state of the primary donor in membranes of $H$. chlorum, was greater than $\mid \mathrm{DI} / 3$ and larger than that of ${ }^{3} \mathrm{BChl} g$ in organic solvents. This difference was tentatively attributed to a difference in coordination of the central magnesium atom [35]. Generally, when the value of $\mid \mathrm{El}$ exceeds $|\mathrm{D}| / 3$, the labeling of the axes is changed so that the largest principal value of the ZFS tensor corresponds to the $\mathrm{z}$-direction. However, we have maintained the same assignment of the $|\mathrm{D}|-|\mathrm{E}|$ and the $|\mathrm{D}|+|\mathrm{E}|$ transitions as in Vrieze, et al. [35], to allow easier comparison with the earlier work.

The FDMR data collected on the two samples are well described by the same Gaussian components previously reported for anoxic HbRC [38]. The differences between the anoxic and oxygen-exposed samples may be explained in terms of a difference in the relative intensity of the two components. The ${ }^{3} \mathrm{BChl} g$ characterized by the smaller |D| value $\left({ }^{3} \mathrm{BChl} g_{1}\right)$ loses more intensity upon the exposure to oxygen than the one with the larger IDI value $\left({ }^{3} \mathrm{BChl} g_{2}\right)$.

The FDMR detected using the $\mathrm{Chl} a_{\mathrm{F}}$ fluorescence between 670 and $700 \mathrm{~nm}$ reveals weak signals in the anoxic sample (Fig. 6a), that are greatly increased in intensity upon exposure of the sample to oxygen in the dark. The frequencies of their $|\mathrm{D}|-|\mathrm{E}|$ and $|\mathrm{D}|+|\mathrm{E}|$ FDMR transitions are typical of ${ }^{3} \mathrm{Chl} a_{\mathrm{F}}$. [22] The Gaussian deconvolution of the spectra revealed the presence of at least two pools of ${ }^{3} \mathrm{Chl}$ $a_{\mathrm{F}}$ (Fig. 6b). Among them, the triplet detected from the fluorescence of the bluer emitter $\left({ }^{3} \mathrm{Chl} a_{2}\right)$ has ZFS parameters comparable to those of a component identified in other typeI RCs, [23, 39, 40] whereas ${ }^{3} \mathrm{Chl} a_{1}$ has an unusually small IEl value (see Table 2).

The sensitivity of ZFS parameters of Chls to the environment and the coordination of the $\mathrm{Mg}$ (i.e. mono- or bi-ligation), as well as to the number and identity of side groups of the pyrrole rings, is well known (see Table S1

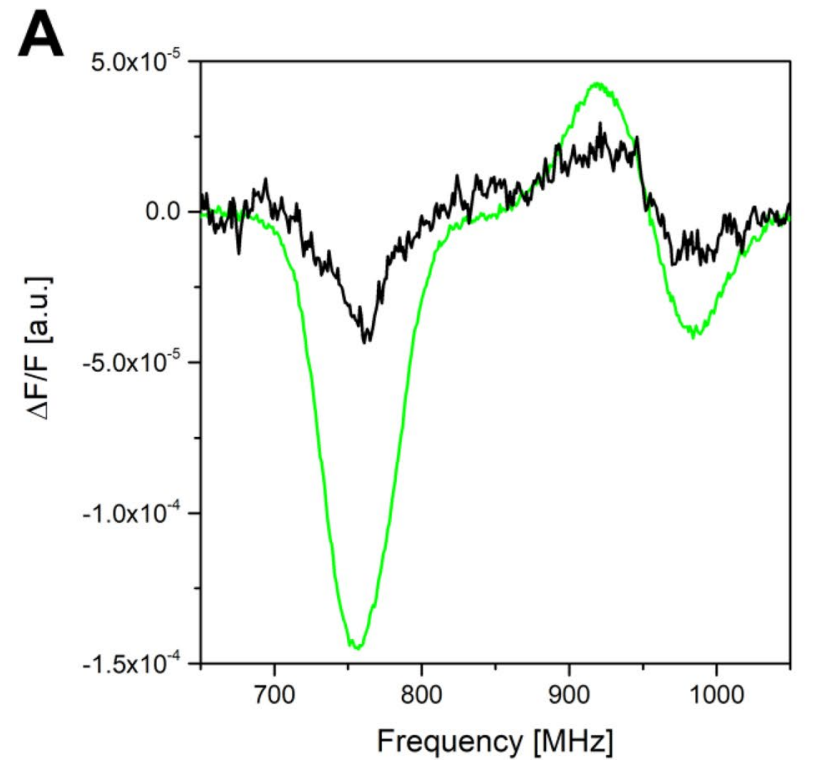

Fig. $6{ }^{3} \mathrm{Chl} a_{\mathrm{F}}$ FDMR spectra of HbRC. a Comparison of the FDMR spectra detected at $680 \mathrm{~nm}$ of samples in anoxic conditions (black line) and exposed for $8 \mathrm{~h}$ to oxygen in the dark (green line). $\mathbf{b}$ FDMR spectra (black lines) of HbRCs exposed for $8 \mathrm{~h}$ to oxygen in the dark detected at different wavelengths in the 670-700 nm range,
B

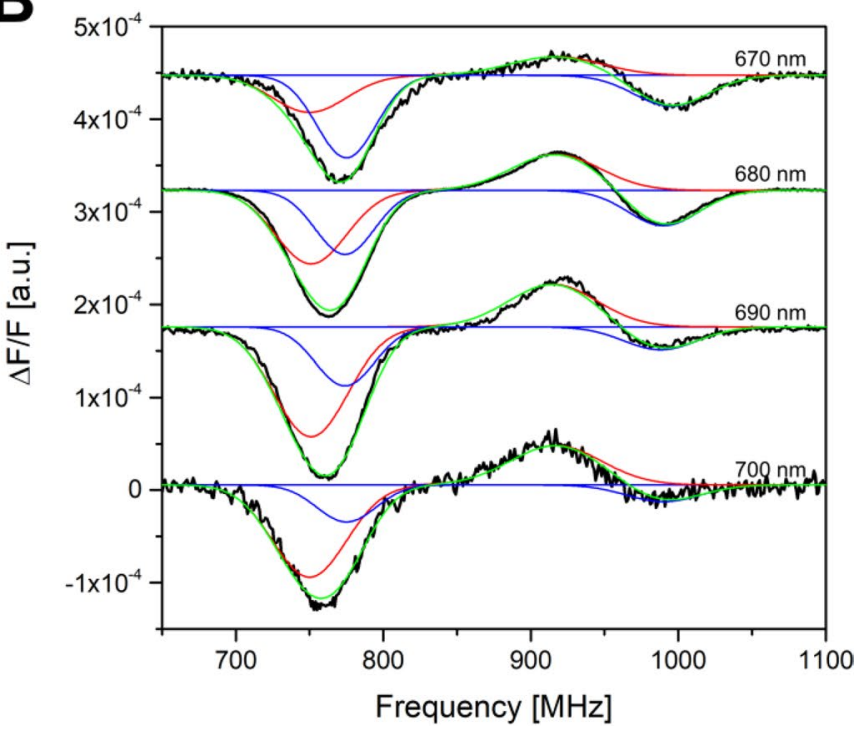

as indicated. Amplitude modulation $33 \mathrm{~Hz}$, time constant $100 \mathrm{~ms}$, temperature $1.8 \mathrm{~K}$. Spectra vertically shifted for better comparison. Reconstruction (green) of the experimental spectra with Gaussian components (blue and red). Fitting parameters reported in Table 2
Table 2 Zero-field splitting parameters of ${ }^{3} \mathrm{Chl} a_{\mathrm{F}}$ in oxygen-exposed $\mathrm{HbRCs}$ from global deconvolution of FDMR data (see Fig. 6b)

\begin{tabular}{|c|c|c|c|c|c|c|}
\hline \multirow[t]{2}{*}{ Triplet } & \multicolumn{2}{|l|}{$|\mathbf{D}|-|\mathbf{E}|$} & \multicolumn{2}{|l|}{$|\mathbf{D}|+|\mathbf{E}|$} & \multirow[t]{2}{*}{$|\mathbf{D}|\left[\mathrm{cm}^{-1}\right]$} & \multirow[t]{2}{*}{$|\mathbf{E}|\left[\mathrm{cm}^{-1}\right]$} \\
\hline & Peak [MHz] & $\begin{array}{l}\text { FWHM } \\
{[\mathrm{MHz}]}\end{array}$ & Peak [MHz] & $\begin{array}{l}\text { FWHM } \\
{[\mathrm{MHz}]}\end{array}$ & & \\
\hline Chl $a_{\mathrm{F} 1}$ & 750 & 50 & 915 & 62 & 0.0277 & 0.00275 \\
\hline Chl $a_{\mathrm{F} 2}$ & 775 & 40 & 990 & 50 & 0.0294 & 0.00358 \\
\hline
\end{tabular}

Estimated error $\pm 0.5 \%$ 
in Supporting information, which reports the ZFS parameters of Chl $a$ triplet state in different solvents). However, a full rationalization of the observed effects is still lacking. In addition, the signs of the observed FDMR transitions have be reported to have some variability. The commonest case for ${ }^{3} \mathrm{Chl} a / b$ is that of the same sign for both the $|\mathrm{D}|+|\mathrm{E}|$ and the $|D|-|E|$ FDMR transitions. However, a few cases have been reported in which the signs of the two transitions are opposite [41]. Possible causes are uncommon ligation of the chlorin ring, presence of hydrogen bonding to water molecules and interaction with neighboring pigments. All these factors may influence the rate of ISC to the $\mathrm{Z}$ level. For instance, we recently reported a ${ }^{3} \mathrm{Chl} a$ FDMR spectrum having this characteristic, for ${ }^{3} \mathrm{Chl} a$ in the water-soluble chlorophyll protein (WSCP) [24]. On the basis of the differences observed in the FDMR spectra, it is likely that Chl $a_{\mathrm{F} 1}$ and $\mathrm{Chl} a_{\mathrm{F} 2}$ reside in significantly different binding pockets.

No FDMR signals were observed at the known resonance frequencies of carotenoid triplet states, [22] indicating that the bound 4,4'-diaponeurosporene molecule does not act as a ${ }^{3} \mathrm{BChl} g$ quencher at low temperature.

\subsection{Triplet-singlet spectra}

To aid in assigning the HbRC chromophores in which the triplet state is populated to specific absorbing species, microwave-induced triplet-minus-singlet (T-S) spectra have been recorded and analyzed. The ${ }^{3} \mathrm{BChl} g \mathrm{~T}-\mathrm{S}$ spectra reported in Fig. 7 were measured by selecting the resonance at $450 \mathrm{MHz}$ corresponding to the maximum of the $|\mathrm{D}|-|\mathrm{E}|$ transition in the ${ }^{3}$ BChl $g$ FDMR spectra (Fig. 5). The anoxic sample, for which the T-S spectrum have been collected in an extended wavelength range, shows a broad positive signal between 450 and $720 \mathrm{~nm}$ due to triplet-triplet $\left(\mathrm{T}_{0} \rightarrow \mathrm{T}_{\mathrm{n}}\right)$ absorption, interrupted by a negative feature between 560 and $595 \mathrm{~nm}$ that originates from the bleaching of the BChl $g$ singlet absorption $\left(\mathrm{S}_{0} \rightarrow \mathrm{S}_{2}, Q_{x}\right.$ band). BChl $g$ triplet-triplet absorption bands are also the source of the positive signals in the red-most part of the spectra $(\lambda>825 \mathrm{~nm})$. The intense negative signals in the $Q_{y}$ region correspond to the bleaching of the singlet absorption of this band, with two peaks at 796 and $813 \mathrm{~nm}$ that are expected to originate from the simultaneous contribution of different BChls $g$, as both the ${ }^{3} \mathrm{BChl}$ $g$ pools identified in the FDMR spectra are in resonance at $450 \mathrm{MHz}$.

For the oxygen-exposed sample, the T-S spectrum has been collected in the $Q_{y}$ region only (Fig. 7b). Upon oxidation, the intensity of the signal is found to decrease, indicating that the ${ }^{3} \mathrm{BChl} g$ yield decreases as the conversion of BChl $g$ into $\mathrm{Chl} a_{\mathrm{F}}$ revealed by the change in the absorbance [5-8] occurs. Analogous to the FDMR results (Fig. 5), the relative intensity of the two peaks is different in the oxygenexposed and anoxic samples, with the redder peak displaying a more marked loss in intensity upon exposure of the complex to oxygen.

To disentangle the overlapping contributions in this region of the two ${ }^{3} \mathrm{BChl} g$ components identified from the global deconvolution of the FDMR spectra (Fig. 5),
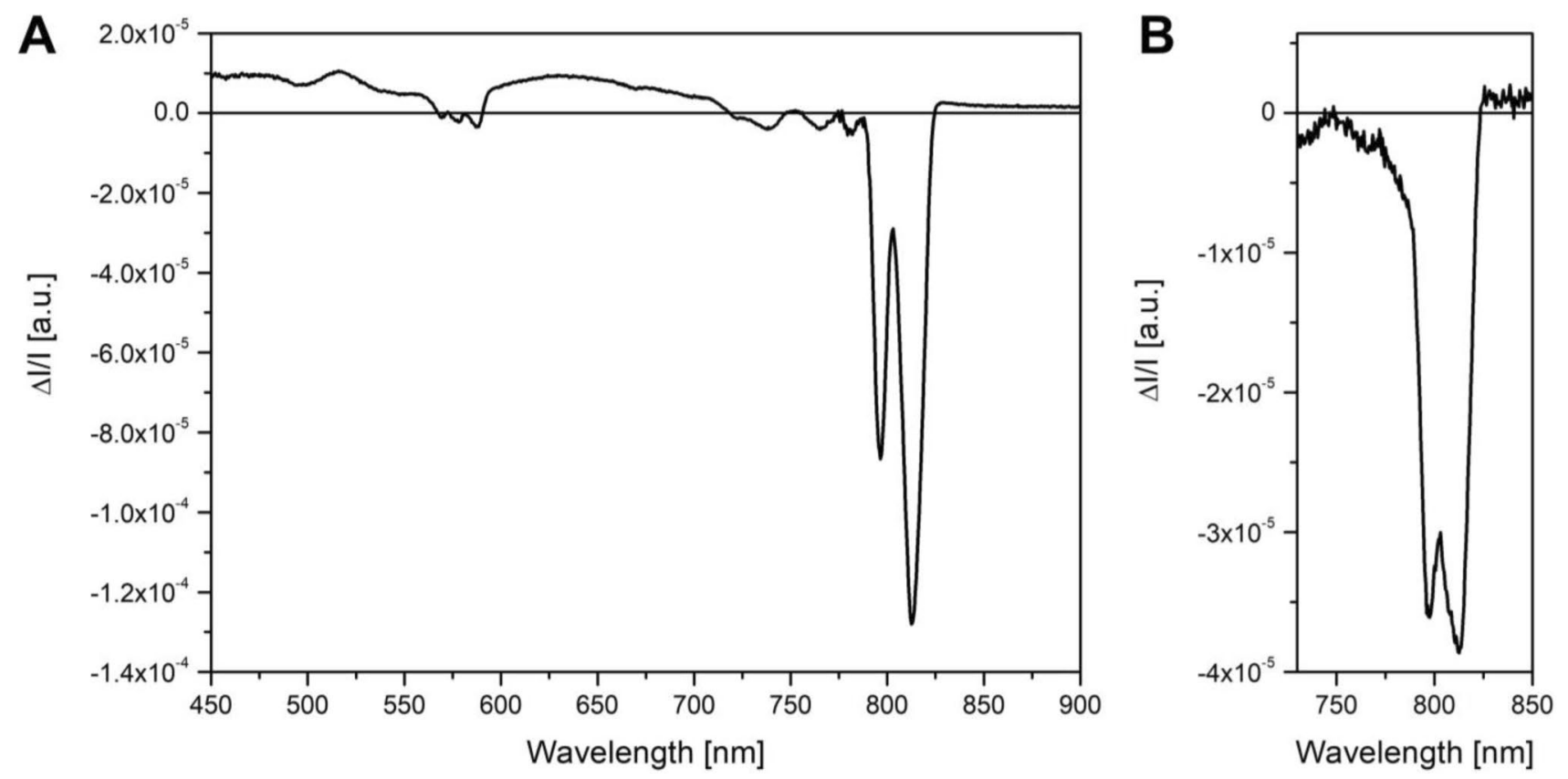

Fig. 7 T-S spectrum of ${ }^{3} \mathrm{BChl} g$. a anoxic conditions, $\mathbf{b} 8 \mathrm{~h}$ of exposure to oxygen in the dark. Resonance frequency $450 \mathrm{MHz}$, amplitude modulation $33 \mathrm{~Hz}$, time constant $1 \mathrm{~s}$, temperature $1.8 \mathrm{~K}$ 
we recorded additional $\mathrm{T}-\mathrm{S}$ spectra with resonance conditions selective for ${ }^{3} \mathrm{BChl} g_{1}(910 \mathrm{MHz})$ and ${ }^{3} \mathrm{BChl} g_{2}$ $(955 \mathrm{MHz})$. The resulting spectra revealed that ${ }^{3} \mathrm{BChl} g_{2}$ has a $\mathrm{T}-\mathrm{S}$ spectrum with only a single bleaching peaking at $799 \mathrm{~nm}$ and no signatures of excitonic interaction (blue spectra in Fig. 8), while ${ }^{3} \mathrm{BChl} g_{1}$ displays a more complex T-S spectrum with two negative peaks and a positive feature in the middle (red spectra in Fig. 8), that can be attributed most likely to a change in the excitonic coupling [24, 41-43]. In fact, upon triplet formation, the exciton bands are expected to bleach while positive bands are expected to appear due to the subtraction of the $\mathrm{BChl}$ carrying the triplet state from the exciton interaction with nearby BChls.

In the air-exposed sample, the increased intensity of ${ }^{3} \mathrm{Chl}$ $a_{\mathrm{F}}$ was sufficient to record its $\mathrm{T}-\mathrm{S}$ spectrum, at a resonance condition corresponding to the maximum of the $|\mathrm{D}|-|\mathrm{E}|$ transitions in the ${ }^{3} \mathrm{Chl} a_{\mathrm{F}}$ FDMR spectra (760 MHz). The resulting spectrum (Fig. 9) of the Chl $a Q_{y}$ band region, revealed a bleaching peaking at $670 \mathrm{~nm}$, with no signatures of excitonic interaction with other Chls.

\section{Discussion}

The selectivity of ODMR spectroscopy and the ability to associate the optical properties of a molecule with the magnetic properties of its triplet state, allow this information to

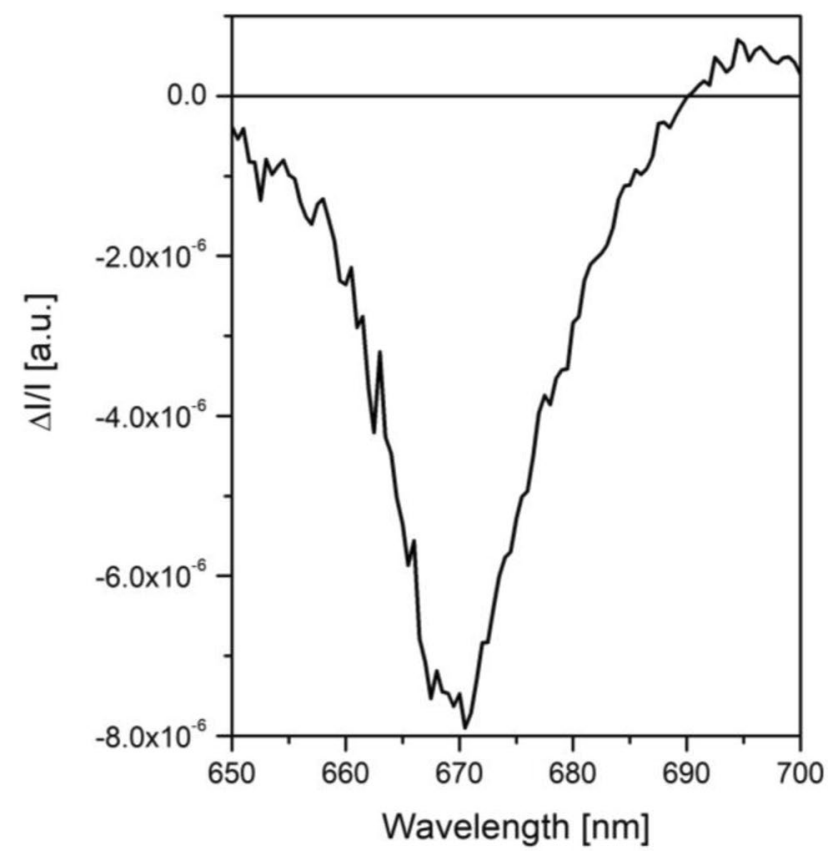

Fig. $9{ }^{3} \mathrm{Chl} a_{\mathrm{F}} \mathrm{T}-\mathrm{S}$ spectrum (sample exposed to oxygen for $8 \mathrm{~h}$ in the dark). Resonance frequency $760 \mathrm{MHz}$, amplitude modulation $33 \mathrm{~Hz}$, time constant $1 \mathrm{~s}$, temperature $1.8 \mathrm{~K}$

be correlated with the three-dimensional arrangement of the pigments in the complex given by the $\mathrm{X}$-ray crystal structure of the H. modesticaldum $\mathrm{RC}$, [12] so that the two ${ }^{3} \mathrm{BChl} \mathrm{g}$
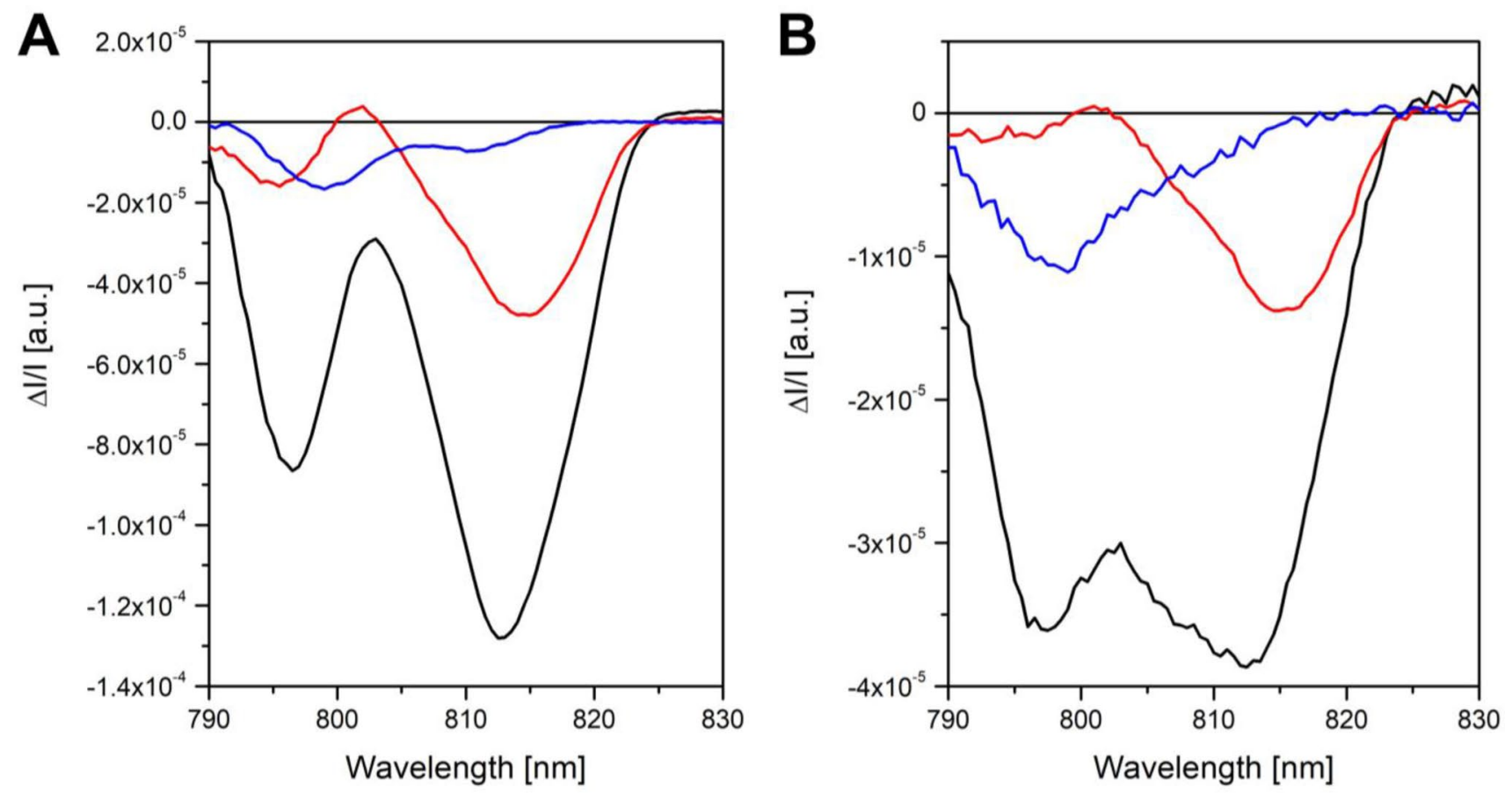

Fig. $8{ }^{3} \mathrm{BChl} g$ T-S spectrum of sample in a anoxic conditions, or $\mathbf{b}$ exposed to oxygen for $8 \mathrm{~h}$ in the dark. Resonance frequencies $450 \mathrm{MHz}$ (black lines), $910 \mathrm{MHz}$ (red lines), and $955 \mathrm{MHz}$ (blue lines). Amplitude modulation $33 \mathrm{~Hz}$, time constant $1 \mathrm{~s}$, temperature $1.8 \mathrm{~K}$ 
pools can be assigned to specific chromophores bound by the complex.

The first characteristic that we employed to narrow the assignment was the differential sensitivity to oxygen. As we found that the two ${ }^{3} \mathrm{BChl} g$ pools differ in this regard, we inspected the exposure of the ethylidene group of the 29 BChls $g$ bound by each half of the homodimeric complex (the results are summarized in Table 3). Eighteen of them were found to have the ethylidene group on the surface of the complex, and six more where found to have this group pointing toward the exterior, close to the surface. Among these exposed and partially exposed BChls, fifteen were found to have their ethylidene groups in the interior of the membrane, which is characterized by a higher local concentration of oxygen [44], whereas the remaining nine have this oxygensensitive group on the cytoplasm or cell exterior surface of the membrane.

Only a small group of five BChls $g$ were found to point their ethylidene group towards the interior of the complex, and we postulate that this might result in a partial shielding of this group from interaction with oxygen. ${ }^{3} \mathrm{BChl} g_{2}$, being less affected by the exposure to oxygen, is likely to be localized within this group of pigments or alternatively may be exposed to the water phase.

Another important characteristic that distinguishes the two pools of BChl $g$ molecules in which the triplet state is formed is the strength of the excitonic coupling with the surrounding BChls. This coupling is reliably determinable from the profile of their T-S spectra. The cumulative spectrum of the two pools (Fig. 7a) is featureless in the $650-700 \mathrm{~nm}$ region, therefore neither of the ${ }^{3} \mathrm{BChls} g$ is in close contact to a Chl $a_{\mathrm{F}}$, thus excluding the possibility that the pigments could be part of the electron transport chain (BChls $g 1001$ and $g 1002$, which correspond to $\mathrm{P} 800$ and $\mathrm{A}_{0}$, respectively) and indicating that they should be identified with BChls $g$ belonging to the antenna system of the complex. In addition, our spectroscopic results show no features that can be assigned to carotenoid molecules. Since carotenoids are known to be able to quench ${ }^{3} \mathrm{BChl}$ triplet states when they are located in close proximity to them, a localization of the triplet state on one of the BChls in close contact with the two diaponeurosporene molecules is unlikely. Thus, we can

Table 3 Excitonic coupling strength and degree of exposure of the ethylidene groups the of the $29 \mathrm{BChl} g$ binding site in the H. modesticaldum RC crystallographic structure [12]

\begin{tabular}{|l|l|l|l|}
\hline & $\begin{array}{l}\text { Weakly interacting } \\
\left(\mathbf{V}<\mathbf{5 0} \mathbf{c m}^{-\mathbf{1}}\right)\end{array}$ & $\begin{array}{l}\text { Interacting } \\
\left.\mathbf{( 5 0} \mathbf{~ c m}^{-\mathbf{-}}<\mathbf{V}<\mathbf{1 5 0} \mathbf{~ c m}^{-\mathbf{1}}\right)\end{array}$ & $\begin{array}{l}\text { Strongly interacting } \\
\left(\mathbf{V}>\mathbf{1 5 0} \mathbf{c m}^{-\mathbf{1}}\right)\end{array}$ \\
\hline $\begin{array}{l}\text { Exposed to the } \\
\text { water phase }\end{array}$ & $g 1010$ & $g 102 ; g 1011 ; g 1012 ; g 1027$ & $g 1024$ \\
\hline $\begin{array}{l}\text { Partially } \\
\text { exposed to the } \\
\text { water phase }\end{array}$ & $g 1004 ; g 1017$ & $g{ }^{\prime} 1001$ \\
\hline $\begin{array}{l}\text { Exposed to the } \\
\text { membrane }\end{array}$ & $g 1022 ; g 1023$ & $\begin{array}{l}g 103 ; g 1006 ; g 1007 ; g 1009 ; \\
g 1013 ; \quad g 1014 ; \quad g 1015 ; \\
g 1016 ; g 1019\end{array}$ & $g 1025$ \\
\hline $\begin{array}{l}\text { Partially } \\
\text { exposed to the } \\
\text { membrane }\end{array}$ & $g 1008 ; g 1018 ; g 1028$ & \\
\hline Buried & $g 1021$ & $g 1002 ; g 1005 ; \quad g 1020 ;$ & \\
\hline
\end{tabular}

The two lowest exciton clusters in the antenna portion of the RC are colored in orange ( $\left.g^{\prime} 1005-g 1020-g 1028\right)$ and red ( $g$ '1011- $g$ 1016- $g$ 1017). The BChl $g$ binding site assigned to ${ }^{3} \mathrm{BChl} g_{1}$ and ${ }^{3} \mathrm{BChl} g_{2}$ (BChls $g 1017$ and $g 1021$ or $g 1010$, respectively) are underlined 

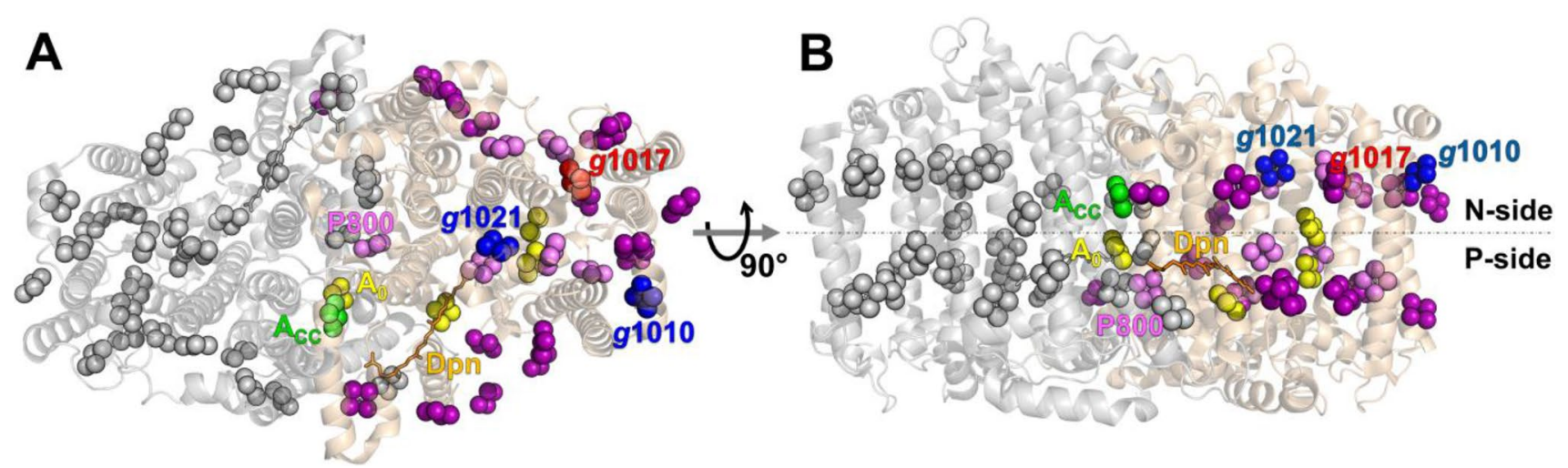

Fig. 10 a $\mathrm{N}$-side view and $\mathbf{b}$ membrane plane view of the crystallographic structure of HbRC [12]. Only the nitrogen atoms of the tetrapyrroles are shown as spheres, for clarity. Chl $a_{\mathrm{F}}$, green, exposed BChls $g$, purple; half-buried BChls $g$, pink; buried BChls $g$, yellow;

eliminate BChls $g 1007, g 1022, g 1026$, and $g 1028$ which have $\pi-\pi$ distances to the carotenoids that are shorter than $6 \AA$.

Analyzing the $Q_{y}$ region of their T-S spectra, the two triplet pools were found to be localized on BChls $g$ that differ strongly in their optical properties (see Fig. 8). The component characterized by the larger IDI value, $\left({ }^{3} \mathrm{BChl}\right.$ $g_{2}$ ), was found to have shorter wavelength absorbance, with weak or no coupling with the surrounding BChls $g$, whereas ${ }^{3} \mathrm{BChl} g_{1}$ appeared to be localized on a BChl $g$ with excitonic coupling of moderate strength (about $200 \mathrm{~cm}^{-1}$ ) in a J-like geometry, as the more intense negative band is the one at longer wavelength [41-43]. Based on these observations, we performed calculations of the excitonic interactions in the framework of the point dipole approximation using the crystallographic coordinates (for details, see "material and methods"). The results are reported in Fig. S1 and Table S2 and summarized in Table 3. Focusing on the pigment clusters characterized by low energy, we found that the lowest exciton corresponds to the P800 special pair ( $g^{\prime} 1001$ dimer), the next in energy comprises buried pigments close to the carotenoid ( $g$ '1005-g1020-g1028, orange in Table 3), whereas the third one is shared by three exposed pigments ( $g$ 1011-g1016- $g 1017$, red in Table 3). In the latter, the central BChl $g 1017$ carries most of the oscillatory strength (Fig. $\mathrm{S} 1$ ), thus the triplet localization is most likely to occur at this site. Remarkably, the localization of the triplet state on BChl $g 1017$ leads to an expected T-S spectrum that displays the same characteristics as the observed ${ }^{3} \mathrm{BChl} g_{1}$ spectrum (see Fig. S2D). Therefore, we attribute the observed ${ }^{3} \mathrm{BChl}$ $g_{1}$ component to BChl $g 1017$. For comparison, we note that this site corresponds to the B21/A23 sites in PSI [45], (see Fig. 10).
BChls $g 1010$ and $g 1021$, blue; BChl $g 1017$, red. Diaponeurosporene (Dpn) are shown as sticks, and the protein scaffold is shown in beige cartoons. One of the monomers is colored in gray

The microwave-induced $\mathrm{T}-\mathrm{S}$ spectrum of the other observed triplet state, ${ }^{3} \mathrm{BChl} g_{2}$, shows no features due to exciton couplings, indicating that only weak interactions with any surrounding BChls (i.e., weaker than $50 \mathrm{~cm}^{-1}$ ) are present. This allows us to assign the triplet state to BChl $g 1021$ (B26/A28 sites in PSI [45]), the only one having this characteristic among the five identified as buried (see Table 3 and Fig. 10). Alternatively, BChl $g 1010$ (B8/ A8 sites in PSI [45]) could be considered since it has only weak interactions with the surrounding pigments and its ethylidene group is exposed to the cytoplasm where oxygen concentration is expected to be lower.

In contrast to oxygenic photosynthetic organisms, $H$. modesticaldum employs a photosynthetic apparatus that is sensitive to the exposure towards molecular oxygen even in the absence of light, due to the susceptibility of BChls $g$ to oxidation. BChls [ $g 1021$ (or $g 1010$,), and $g$ 1017] when oxidized produce $\mathrm{Chl} a_{\mathrm{F}}$. Due to the inability of $\mathrm{Chl}$ $a_{\mathrm{F}}$ to funnel excitation energy to the reaction center, oxidized HbRCs have an high Chl $a_{\mathrm{F}}$ triplet yield that was observed in the ODMR spectra (Figs. 6a, 9) as well as in earlier transient EPR experiments [46]. Under illumination and in presence of oxygen, this may lead to an increased production of reactive oxygen species. However, in the anoxygenic ecological niche occupied by $H$. modestical$d u m$, this is not expected to be a significant liability for the organism. Accordingly, HbRC binds only one carotenoid, in comparison to the 15 [47] that perform a pivotal photo-protective role $[39,48]$ in plant PSI. Carotenoid photo-protective action can be performed by means of ${ }^{3}(\mathrm{~B})$ Chls quenching through triplet-triplet energy transfer [49, 50] as well as by direct deactivation of singlet oxygen upon its photosensitization from ${ }^{3}(\mathrm{~B}) \mathrm{Chls}$ [51]. The lack of FDMR signals attributable to the triplet state of the 
diaponeurosporene molecules rules out the triplet-triplet energy transfer mechanism from taking place in HbRC.

\section{Conclusion}

FDMR and ADMR on partially oxidized and anoxic control samples of HbRCs have given insight into the triplet state locations within the complex. According to our assignments, both ${ }^{3} \mathrm{BChls} g$ formed in HbRC are localized on the cytoplasmatic side (N-side [12]) of the complex, not far apart from each other (Fig. 10). They are located far away from both the electron transport chain and the carotenoid bound to the complex. In the eventuality of exposure to molecular oxygen, the singlet oxygen photosensitization by these ${ }^{3} \mathrm{BChls} g$ (or by ${ }^{3} \mathrm{Chls} a_{\mathrm{F}}$ derived from their dark oxidation) is expected to lead to the oxidation of pigments and peptides nearby the site of production, as the high reactivity of singlet oxygen is expected to prevent an extended diffusion. Thus, a sacrificial role for these peripheral BChls $g$ can be envisioned, as they may help in limiting the possible dangerous effects that singlet oxygen could cause to portions of the complex closer to the electron transfer chain upon transient oxygen exposure. To verify this assumption, the analysis of the effects of oxidation to the complex not only in the dark exposure to oxygen but also in the light will be of great interest.

Supplementary Information The online version contains supplementary material available at https://doi.org/10.1007/s43630-021-00049-3.

Funding The work was supported by the University of Padova in the form of a P-DiSC-2019 project to A.A. and D.C., by NSERC in the form of a Discovery Grant to A.v.d.E., and by a grant from the Photosynthetic Systems Program, Chemical Sciences, Geosciences, \& Biosciences (CSGB) Division, US Department of Energy (DESC0010575) to J.H.G.

\section{Declarations}

Conflict of interest The authors declare that they have no conflict of interest.

\section{References}

1. Gest, H., \& Favinger, J. L. (1983). Heliobacterium chlorum, an anoxygenic brownish-green photosynthetic bacterium containing a "new" form of bacteriochlorophyll. Archives of Microbiology, $136,11-16$

2. Kimble, L. K., \& Madigan, M. T. (1992). Nitrogen fixation and nitrogen metabolism in heliobacteria. Archives of Microbiology, $158,155-161$

3. Brockmann, H., \& Lipinski, A. (1983). Bacteriochlorophyll g. A new bacteriochlorophyll from Heliobacterium chlorum. Archives of Microbiology, 136, 17-19
4. Tester, M., \& Morris, C. (1987). The penetration of light through soil. Plant, Cell and Environment, 10, 281-286

5. Beer-Romero, P., Favinger, J. L., \& Gest, H. (1988). Distinctive properties of bacilliform photosynthetic heliobacteria. FEMS Microbiology Letters, 49, 451-454

6. Michalski, T. J., Hunt, J. E., Bowman, M. K., Smith, U., Bardeen, K., Gest, H., Norris, J. R., \& Katz, J. J. (1987). Bacteriopheophytin $\mathrm{g}$ : properties and some speculations on a possible primary role for bacteriochlorophylls $\mathrm{b}$ and $\mathrm{g}$ in the biosynthesis of chlorophylls. Proceedings of the National Academy of Sciences, 84, 2570-2574

7. Kobayashi, M., Hamano, T., Akiyama, M., Watanabe, T., Inoue, K., Oh-Oka, H., Amesz, J., Yamamura, M., \& Kise, H. (1998). Light-independent isomerization of bacteriochlorophyll $\mathrm{g}$ to chlorophyll a catalyzed by weak acid in vitro. Analytica Chimica Acta, 365, 199-203

8. Ferlez, B., Dong, W., Siavashi, R., Redding, K., Hou, H. J. M., Golbeck, J. H., \& van der Est, A. (2015). The effect of bacteriochlorophyll g oxidation on energy and electron transfer in reaction centers from Heliobacterium modesticaldum. The Journal of Physical Chemistry B, 119, 13714-13725

9. van de Meent, E. J., Kobayashi, M., Erkelens, C., van Veelen, P. A., Amesz, J., \& Watanabe, T. (1991). Identification of 81-hydroxychlorophyll a as a functional reaction center pigment in heliobacteria. Biochimica et BiophysicaActa BBA Bioenergetics, 1058, 356-362

10. Trost, J. T., \& Blankenship, R. E. (1989). Isolation of a photoactive photosynthetic reaction center-core antenna complex from Heliobacillus mobilis. Biochemistry, 28, 9898-9904

11. Liebl, U., Mockensturm-Wilson, M., Trost, J. T., Brune, D. C., Blankenship, R. E., \& Vermaas, W. (1993). Single core polypeptide in the reaction center of the photosynthetic bacterium Heliobacillus mobilis: structural implications and relations to other photosystems. Proceedings of the National Academy of Sciences, 90, 7124-7128

12. Gisriel, C., Sarrou, I., Ferlez, B., Golbeck, J. H., Redding, K. E., \& Fromme, R. (2017). Structure of a symmetric photosynthetic reaction center-photosystem. Science, 357, 1021-1025

13. Hiraishi, A. (1989). Occurrence of menaquinone as the sole isoprenoid quinone in the photosynthetic bacterium Heliobacterium chlorum. Archives of Microbiology, 151, 378-379

14. Kleinherenbrink, F. A. M., Ikegami, I., Hiraishi, A., Otte, S. C. M., \& Amesz, J. (1993). Electron transfer in menaquinone-depleted membranes of Heliobacterium chlorum. Biochimica et Biophysica Acta BBA Bioenergetics, 1142, 69-73

15. Brettel, K., Leibl, W., \& Liebl, U. (1998). Electron transfer in the heliobacterial reaction center: evidence against a quinone-type electron acceptor functioning analogous to A1 in photosystem I. Biochimica et Biophysica Acta BBA Bioenergetics, 1363, 175-181

16. Kondo, T., Matsuoka, M., Azai, C., Kobayashi, M., Itoh, S., \& Ohoka, H. (2018). Light-induced electron spin-polarized (ESP) EPR signal of the $\mathrm{P} 800$ + Menaquinone-radical pair state in oriented membranes of Heliobacterium modesticaldum: role/location of Menaquinone in the Homodimeric Type I Reaction Center. The Journal of Physical Chemistry B. https://doi.org/10.1021/acs.jpcb. $7 \mathrm{~b} 12171$

17. Neerken, S., \& Amesz, J. (2001). The antenna reaction center complex of heliobacteria: composition, energy conversion and electron transfer. Biochimica et Biophysica Acta BBA Bioenergertics, 1507, 278-290

18. van der Est, A., Hager-Braun, C., Leibl, W., Hauska, G., \& Stehlik, D. (1998). Transient electron paramagnetic resonance spectroscopy on green-sulfur bacteria and heliobacteria at two microwave frequencies. Biochimica et Biophysica Acta BBA Bioenergetics, 1409, 87-98 
19. Kashey, T. S., Luu, D. D., Cowgill, J. C., Baker, P. L., \& Redding, K. E. (2018). Light-driven quinone reduction in heliobacterial membranes. Photosynthesis Research, 138, 1-9

20. Heinnickel, M., Agalarov, R., Svensen, N., Krebs, C., \& Golbeck, J. H. (2006). Identification of $F_{X}$ in the heliobacterial reaction center as a [4Fe-4S] cluster with an $\mathrm{S}=3 / 2$ ground spin state. Biochemistry, 45, 6756-6764

21. Vassiliev, I. R., Jung, Y. S., Mamedov, M. D., AYu, S., \& Golbeck, J. H. (1997). Near-IR absorbance changes and electrogenic reactions in the microsecond-to-second time domain in Photosystem I. Biophysical Journal, 72, 301-315

22. Carbonera, D., Giacometti, G., \& Agostini, G. (1992). FDMR of Carotenoid and Chlorophyll triplets in light-harvesting complex LHCII of spinach. Applied Magnetic Resonance, 3, 859-872

23. Santabarbara, S., Bordignon, E., Jennings, R. C., \& Carbonera, D. (2002). Chlorophyll triplet states associated with Photosystem II of thylakoids. Biochemistry, 41, 8184-8194

24. Agostini, A., Palm, D. M., Paulsen, H., \& Carbonera, D. (2018). Optically detected magnetic resonance of the chlorophyll triplet state in the water-soluble chlorophyll protein from Lepidium virginicum. Evidence for excitonic interaction among the four pigments. The Journal of Physical Chemistry B, 122, 6156-6163

25. Carbonera, D. (2009). Optically detected magnetic resonance (ODMR) of photoexcited triplet states. Photosynthesis Research, $102,403-414$

26. Goovaerts, E. (2017). Optically detected magnetic resonance (ODMR). eMagRes, 6, 343-358

27. Hoff, A. J. (1996). Advances in photosyntheis. In J. Amesz \& A. J. Hoff (Eds.), Biophysical techniques in photosynthesis. (Vol. 3) Dordrecht: Kluwer Academic Publishers.

28. Den Blanken, H. J., Meiburg, R. F., \& Hoff, A. J. (1984). Polarized triplet-minus-singlet absorbance difference spectra measured by absorbance detected magnetic resonance. An application to photosynthetic reaction centers. Chemical Physics Letters, 105, 336-342

29. López-Tarifa, P., Liguori, N., van den Heuvel, N., Croce, R., \& Visscher, L. (2017). Coulomb couplings in solubilised light harvesting complex II (LHCII): challenging the ideal dipole approximation from TDDFT calculations. Physical Chemistry Chemical Physics: PCCP, 19, 18311-18320

30. Frähmcke, J. S., \& Walla, P. J. (2006). Coulombic couplings between pigments in the major light-harvesting complex LHC II calculated by the transition density cube method. Chemical Physics Letters, 430, 397-403

31. Kitoh-Nishioka, H., Shigeta, Y., Itoh, S., \& Kimura, A. (2020). Excitonic coupling on a heliobacterial symmetrical type-I reaction center: comparison with photosystem I. The Journal of Physical Chemistry B, 124, 389-403

32. Knox, R. S., \& Spring, B. Q. (2007). Dipole strengths in the chlorophylls. Photochemistry and Photobiology, 77, 497-501

33. Madjet, M. E., Abdurahman, A., \& Renger, T. (2006). Intermolecular coulomb couplings from ab initio electrostatic potentials: application to optical transitions of strongly coupled pigments in photosynthetic antennae and reaction centers. The Journal of Physical Chemistry B, 110, 17268-17281

34. Kimura, A., \& Itoh, S. (2018). Theoretical model of exciton states and ultrafast energy transfer in heliobacterial type I homodimeric reaction center. The Journal of Physical Chemistry B, 122, 11852-11859

35. Lin, S., Chiou, H.-C., Kleinherenbrink, F. A., \& Blankenship, R. E. (1994). Time-resolved spectroscopy of energy and electron transfer processes in the photosynthetic bacterium Heliobacillus mobilis. Biophysical Journal, 66, 437-445

36. Vrieze, J., van de Meent, E. J., \& Hoff, A. J. (1998). Triplet properties and interactions of the primary electron donor and antenna chromophores in membranes of Heliobacterium chlorum, Studied with ADMR spectroscopy. Biochemistry, 37, 14900-14909

37. Santabarbara, S., Agostini, A., Casazza, A. P., Zucchelli, G., \& Carbonera, D. (2015). Carotenoid triplet states in photosystem II: coupling with low-energy states of the core complex. Biochimica et Biophysica Acta BBA Bioenergetics, 1847, 262-275

38. Ferlez, B., Agostini, A., Carbonera, D., Golbeck, J. H., \& van der Est, A. (2017). Triplet charge recombination in heliobacterial reaction centers does not produce a spin-polarized EPR spectrum. Zeitschrift für Physikalische Chemie, 231, 593-607

39. Cazzaniga, S., Bressan, M., Carbonera, D., Agostini, A., \& Dallosto, L. (2016). 2016 Differential roles of carotenes and xanthophylls in Photosystem I photoprotection. Biochemistry, 55, 3636-3649

40. Santabarbara, S., Agostini, G., Casazza, A. P., Syme, C. D., Heathcote, P., Böhles, F., Evans, M. C. W., Jennings, R. C., \& Carbonera, D. (2007). Chlorophyll triplet states associated with Photosystem I and Photosystem II in thylakoids of the green alga Chlamydomonas reinhardtii. Biochimica et Biophysica Acta BBA Bioenergetics, 1767, 88-105

41. Den Blanken, H. J., \& Hoff, A. J. (1982). High-resolution optical absorption-difference spectra of the triplet state of the primary donor in isolated reaction centers of the photosynthetic bacteria Rhodopseudomonas sphaeroides R-26 and Rhodopseudomonas viridis measured with optically detected magnetic resonance. Biochimica et Biophysica Acta BBA Bioenergetics, 681, 365-374

42. Carbonera, D., Collareta, P., \& Giacometti, G. (1997). The P700 triplet state in an intact environment detected by ODMR. A well resolved triplet minus singlet spectrum. Biochimica et Biophysica Acta, Bioenergetics, 1322, 115-128

43. Carbonera, D., Giacometti, G., \& Agostini, G. (1994). A well resolved ODMR triplet minus singlet spectrum of P680 from PSII particles. FEBS Letters, 343, 200-204

44. Ligeza, A., Tikhonov, A. N., Hyde, J. S., \& Subczynski, W. K. (1998). Oxygen permeability of thylakoid membranes: electron paramagnetic resonance spin labeling study. Biochimica et Biophysica Acta BBA Bioenergetics, 1365, 453-463

45. Jordan, P., Fromme, P., Witt, H. T., Klukas, O., Saenger, W., \& Krauß, N. (2001). Three-dimensional structure of cyanobacterial photosystem I at $2.5 \AA$ resolution. Nature, 411, 909-917

46. Ferlez, B., Cowgill, J., Dong, W., Gisriel, C., Lin, S., Flores, M., Walters, K., Cetnar, D., Redding, K. E., \& Golbeck, J. H. (2016). Thermodynamics of the electron acceptors in Heliobacterium modesticaldum: an exemplar of an early homodimeric type I photosynthetic reaction center. Biochemistry, 55, 2358-2370

47. Amunts, A., Toporik, H., Borovikova, A., \& Nelson, N. (2010). Structure determination and improved model of plant photosystem I. Journal of Biological Chemistry, 285, 3478-3486

48. Cazzaniga, S., Li, Z., Niyogi, K. K., Bassi, R., \& Dallosto, L. (2012). The Arabidopsis szl1 mutant reveals a critical role of $\beta$-carotene in photosystem I photoprotection. Plant Physiology, $159,1745-1758$

49. Di Valentin, M., Büchel, C., Giacometti, G. M., \& Carbonera, D. (2012). Chlorophyll triplet quenching by fucoxanthin in the fucoxanthin-chlorophyll protein from the diatom Cyclotella meneghiniana. Biochemical and Biophysical Research Communications, 427, 637-641

50. Carbonera, D., Agostini, A., Di Valentin, M., Gerotto, C., Basso, S., Giacometti, G. M., \& Morosinotto, T. (2014). Photoprotective sites in the violaxanthin-chlorophyll a binding Protein (VCP) from Nannochloropsis gaditana. Biochimica et Biophysica Acta BBA-Bioenergetics, 1837, 1235-1246

51. Di Mascio, P., Murphy, M. E., \& Sies, H. (1991). Antioxidant defense systems: the role of carotenoids, tocopherols, and thiols. American Journal of Clinical Nutrition, 53, 194-200 